\title{
Long-Term Health and Work Outcomes of Renal Transplantation and Patterns of Work Status During the End-Stage Renal Disease Trajectory
}

\author{
Sijrike F. van der Mei • Daphne Kuiper • \\ Johan W. Groothoff • Wim J. A. van den Heuvel • \\ Willem J. van Son · Sandra Brouwer
}

Published online: 9 June 2011

(C) The Author(s) 2011. This article is published with open access at Springerlink.com

\begin{abstract}
Introduction The aim of this study was to examine the health- and work outcomes of renal transplant recipients long-term after transplantation as well as the pattern of work status, work ability and disability benefits during the end-stage renal disease (ESRD) trajectory that precedes transplantation. Methods 34 transplant recipients completed interviews 3, 13 months and $>6$ years posttransplantation. Health status (SF-36), work ability (WAI), and fatigue (CIS) were assessed by questionnaires, clinical data were derived from medical charts, and data on functional limitations were extracted from the social security system database. The work status trajectory preceding transplantation was examined retrospectively. Results Of the 34 third wave transplant recipients, $29 \%$ were severely fatigued. Compared with the general working population, recipients experienced worse general health and less vitality. Non-working recipients had worse renal function and general health, and more limitations in physical functioning compared to working recipients. The WAI score indicated moderate work ability for $60 \%$ of the employed
\end{abstract}

\footnotetext{
S. F. van der Mei $(\bowtie)$. J. W. Groothoff .

W. J. A. van den Heuvel · S. Brouwer

Department of Health Sciences, University Medical Center

Groningen, University of Groningen, P.O. Box 196,

9700 AD Groningen, The Netherlands

e-mail: s.f.van.der.mei@med.umcg.nl

S. F. van der Mei · D. Kuiper

Applied Health Research, Department of Health Sciences, University Medical Center Groningen, University of Groningen, Groningen, The Netherlands
}

W. J. van Son

Department of Internal Medicine, Division of Nephrology, University Medical Center Groningen, Groningen,

The Netherlands recipients. Although $67 \%$ were employed (45\% parttime), $30 \%$ of those working still received some disability benefits. Social insurance physicians found variable levels of functional limitations. The mean work status trajectory showed more sickness absence and less work ability during dialysis, but after transplantation, both work status and work ability generally improved. Conclusions Transplant recipients have a compromised health status which leads to functional limitations and disability. Although work status improved after transplantation, a substantial number of the transplant recipients received disability benefits. The negative health consequences of anti-rejection medications may play an important role in long-term work ability. These results indicate that a 'new' kidney has advantages over dialysis with respect to work, but does not necessarily leads to 'normal' work outcomes.

Keywords Renal transplantation - End-stage renal disease · Employment - Disability · Work ability · Fatigue

\section{Introduction}

End-stage renal disease (ESRD) is a complete or near complete failure (i.e., less than $10 \%$ of normal function) of the kidneys. It is a permanent and irreversible condition often featured by a slowly progressive loss of function over a period of months or years. Renal replacement therapy compensates the loss of renal function. Nowadays, renal transplantation has become a routine procedure and is the treatment of choice for ESRD, as it has a better prognosis when compared to dialysis [1,2]. Transplantation offers recipients the potential for restoring a productive and independent life $[3,4]$, although it does not equal complete 
normalization of health. The life-long immunosuppressive regimen, prescribed to prevent allograft rejection, has numerous side-effects that necessitate regular medical checkups [5]. Besides weight gain, hirsutism, mood swings and osteoporosis, patients are confronted with an increased risk for infection, hypertension, neuropathy, cataract and post-transplant diabetes mellitus. These comorbid conditions may lead to functional limitations and work disability.

Despite the burden of ESRD, a significant number of transplant recipients are able to return to work. A review of studies published between 1980 and 2003 showed that employment rates of renal transplant recipients ranged between 18 and $82 \%$ [6]. More recent studies reported employment rates of $25 \%$ [7], 29\% [8], 49\% [9, 10], 52\% [11], and 59\% [12]. Comparison of these rates across the studies is hampered by differences in defining categories of employment (e.g., including full-time students and homemakers) and heterogeneity of study populations with regard to demographic and clinical characteristics [6]. Most of these studies had a cross-sectional design and some studies retrospectively collected data on work status pretransplantation.

To our knowledge, the study of Matas et al. [13] is the only study that examined patterns of work status prospectively. They found that $22 \%$ of the transplant recipients who received disability benefits preceding transplantation returned to full-time work (or school). Of those who dropped out of work after transplantation, 34\% reported being work disabled. Apparently, work limitations remains an issue after transplantation. It is the main reason for not being employed as reported by $68 \%$ of transplant recipients without a paid job [11].

In 2002, we started a follow-up study among renal transplant recipients which aimed to describe changes in social participation (i.e., work, education, household tasks, leisure activities) in the first year after transplantation [14]. Considering work status, we found a rather stable employment rate during the first year after transplantation indicating that those who were able to maintain their job before transplantation did return to work. A substantial proportion of the working transplant recipients, however, did receive additional disability benefits. As little is known about long-term work outcomes after transplantation, we decided to perform a third follow-up wave. The aim of the present study is to examine the long-term health- and work outcomes of renal transplant recipients $>6$ years after transplantation. In addition, the pattern of work status, work ability and disability benefits during the ESRD trajectory that precedes transplantation are examined. To our knowledge, this is the first study that describes the work status trajectory of ESRD patients from diagnosis to longterm after transplantation.

\section{Methods}

Design and Study Population

The current study is a third wave (T3) in a cohort of kidney transplant recipients ( $\geq 18$ years) who were transplanted at the University Medical Centre Groningen (UMCG) between March 1, 2002 and March 31, 2003. Patients with a stable renal allograft function after primary kidney transplantation were eligible. Combined transplant (i.e., kidney/pancreas, kidney/liver) and retransplant recipients were excluded, as were patients unable to understand Dutch. After receiving information during a visit at the outpatient clinic, patients signed informed consent (baseline wave response rate $79 \%$ ). The study was approved by the Medical Ethics Review Committee of the UMCG.

Figure 1 shows the inclusion, eligibility and follow-up data from the cohort of transplant recipients. The baseline data collection wave (T1) was performed at 3 months and the second wave (T2) at 1 year posttransplantation [14]. For the third wave (March and April 2009; $>6$ years posttransplantation), eligibility assessment of the T2 study group $(n=58)$ showed that four recipients $(7 \%)$ had died, three recipients $(5 \%)$ were back on dialysis, and two (3\%) had expressed unwillingness to participate in future studies. Of the remaining 49 eligible recipients, 34 (69\%) agreed to participate. The results presented in this paper are based on these 34 transplant recipients.

Nonresponders were older (mean 55.3 years; mean difference 10.7 years; 95\% CI 3.4-18.1; $P<0.05$ ) but did not differ for gender $(P=0.74)$. An attrition bias analysis, comparing T3 study participants to those who were lost to follow-up $(n=27)$, showed that T3 study participants had a higher educational level (58.8\% upper secondary or tertiary education vs. $29.6 \%$ in the lost to follow-up group; $P=0.02$ ). No differences were found for the other demographic and clinical characteristics as listed in Table 1. With respect to the work outcomes of this study, we found a higher work status in T3 study participants ( $51.5 \%$ vs. $37.5 \%$ in the lost to follow-up group), although not statistically significant $(P=0.29)$. However, transplant recipients who were lost to follow-up more often received disability benefits at baseline $(79.2 \%$ vs. $51.5 \%$ in the $\mathrm{T} 3$ study group; $P=0.03$ ).

\section{Procedure and Measurements}

\section{Socio-Demographic and Clinical Characteristics}

Age, gender and highest attained level of education [15] were assessed at baseline (T1). Data on clinical characteristics were collected at baseline and at $\mathrm{T} 3$ by reviewing medical charts and the Groningen Renal Transplant 


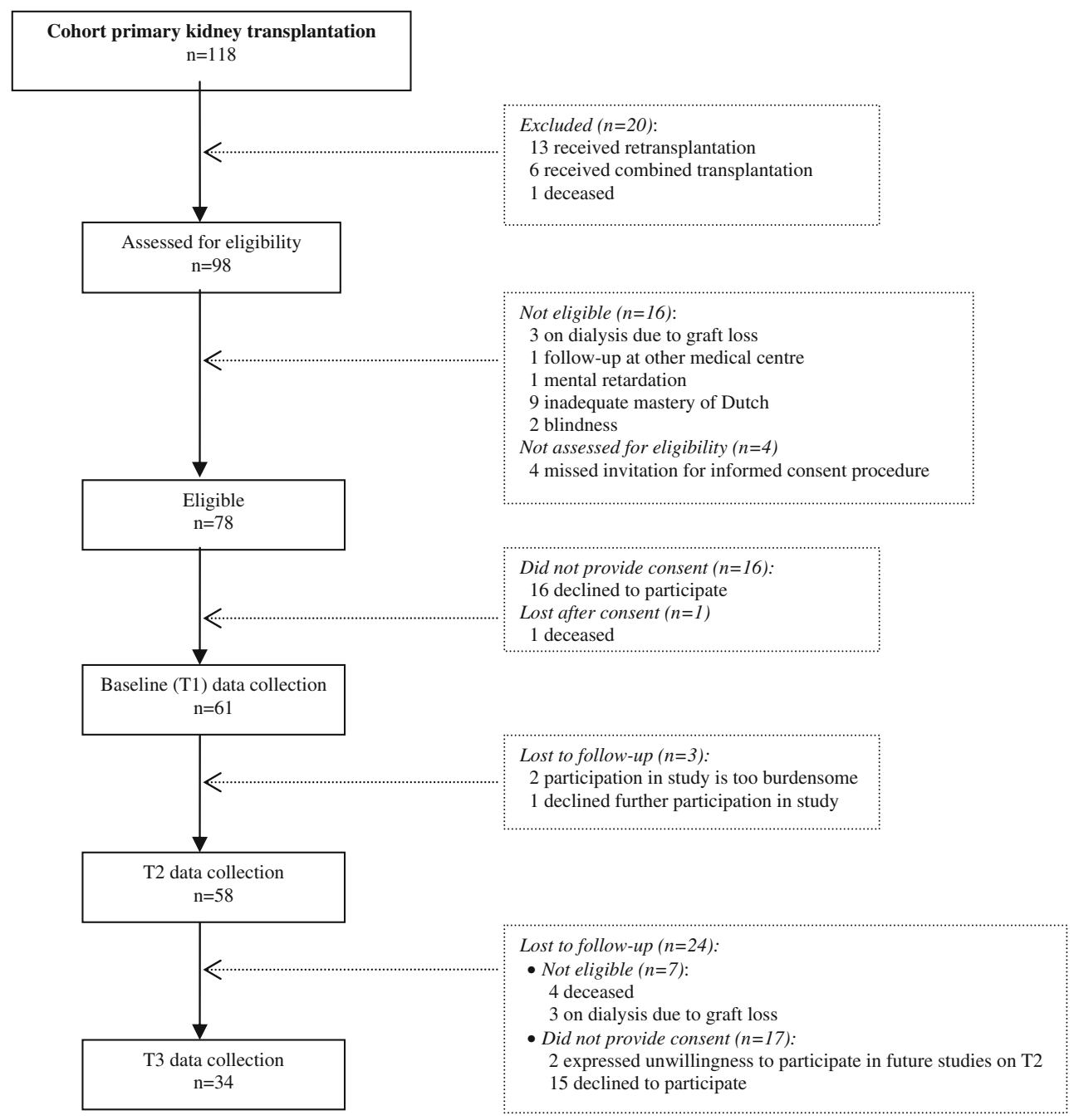

Fig. 1 Flow diagram of inclusion, eligibility and follow-up of renal transplant recipients

Database. Primary renal disease was classified according to the ERA-EDTA [16]. Comorbidity was defined as: (1) diabetes mellitus (insulin or oral antidiabetic drugs dependent); (2) presence of cardiac disease evidenced by a history of cardiovascular events (i.e., previous myocardial infarction, coronary artery bypass grafting, percutaneous transluminal coronary angioplasty, cardiac valve replacement); (3) cerebro vascular disease evidenced by a history of previous cerebro vascular events (i.e., cerebro vascular accident, transient ischemic attack, carotid artery bypass grafting, percutaneous transluminal femora angioplasty, peripheral vascular disease surgery [bypass, embolectomy, amputation]); (4) non-cutaneous malignancy posttransplantation. In addition, we collected data on type of transplantation (cadaveric vs. living), type of dialysis (peritoneal vs. hemodialysis) and duration of dialysis prior to transplantation (years), renal allograft function (estimated glomerular filtration rate (GFR), $\mathrm{mL} / \mathrm{min} / 1.73 \mathrm{~m}^{2}$; calculated by using the abbreviated MDRD equation with serum creatinine measured in $\mathrm{mg} / \mathrm{dL}$ [17]), and anthropometric characteristics.

\section{Health Outcomes}

Data on health outcomes were collected by a standardized self-report questionnaire, sent to participants preceding the T3 interview.

Health status was assessed with the Medical Outcomes Study 36-item Short-Form Health Survey (SF-36) [18] consisting of eight multi-item scales: physical functioning, role limitations due to physical health problems, bodily pain, general health perceptions, vitality, social functioning, role limitations due to emotional problems, and mental health. Higher scores indicate higher levels of functioning and health (range 0-100). In the present study the Cronbach's alphas ranged from 0.69 to 0.91 . SF-36 scores of transplant recipients were compared with normative data of 
Table 1 Socio-demographic, clinical and health status characteristics of the total study group $(n=34)$ and stratified for work outcome in working age patients (18-64 years; $n=30)$

\begin{tabular}{|c|c|c|c|c|}
\hline & Total group $n=34$ & Employed $n=20$ & Non-working $n=10$ & $P$ value \\
\hline Age, mean (SD) & $\begin{array}{l}50.5(11.5) \\
\text { Range 25.0-78.5 }\end{array}$ & $46.2(10.0)$ & $51.6(7.5)$ & 0.14 \\
\hline Gender (male), $n(\%)$ & $19(55.9)$ & $11(55.0)$ & $6(60.0)$ & 1.00 \\
\hline Living arrangement (with others), $n(\%)$ & $31(91.2)$ & $19(95.0)$ & $8(80.0)$ & 0.25 \\
\hline Educational status, $n(\%)$ & & & & 0.43 \\
\hline Primary or lower secondary & $14(41.2)$ & $6(30.0)$ & $5(50.0)$ & \\
\hline Upper secondary or tertiary & $20(58.8)$ & $14(70.0)$ & $5(50.0)$ & \\
\hline \multicolumn{5}{|l|}{ Primary renal disease, $n(\%)$} \\
\hline Glomerulonephritis & $26(76.5)$ & $17(85.0)$ & $7(70.0)$ & 0.69 \\
\hline Renal vascular disease & $1(2.9)$ & $1(5.0)$ & $0(0)$ & $\S$ \\
\hline Polycystic renal disease & $4(11.8)$ & $1(5.0)$ & $1(10.0)$ & $\S$ \\
\hline Other/unkown cause & $3(8.8)$ & $1(5.0)$ & $2(20.0)$ & $\S$ \\
\hline Comorbidity, $n(\%), n=1$ missing & & $n=1$ missing & & \\
\hline Diabetes mellitus & $6(18.2)$ & $2(10.5)$ & $4(40.0)$ & 0.14 \\
\hline Insulin dependent & $2(33.3)$ & $0(0)$ & $2(50.0)$ & \\
\hline Oral antidiabetic drug & $4(66.7)$ & $2(100.0)$ & $2(50.0)$ & \\
\hline Cardiac disease & $3(9.1)$ & $1(5.3)$ & $1(10.0)$ & $\S$ \\
\hline Cerebrovascular disease & $4(12.1)$ & $2(10.5)$ & $0(0)$ & $\S$ \\
\hline Malignancy (non-cutaneous) & $3(9.1)$ & $2(10.5)$ & $1(10.0)$ & $\S$ \\
\hline Type of transplantation, $n(\%)$ & & & & 0.68 \\
\hline Cadaveric & $23(67.6)$ & $14(70.0)$ & $8(80.0)$ & \\
\hline Living & $11(32.4)$ & $6(30.0)$ & $2(20.0)$ & \\
\hline Pre-transplant dialysis, $n(\%)$ & & & & 0.66 \\
\hline Hemodialysis & $10(29.4)$ & $4(20.0)$ & $3(30.0)$ & \\
\hline Peritoneal & $24(70.6)$ & $16(80.0)$ & $7(70.0)$ & \\
\hline Duration of dialysis, in years, median & 3.3 & 3.3 & 4.5 & 0.63 \\
\hline & Range $0.5-7.6$ & & & \\
\hline Time since transplantation, in years, mean (SD) & $6.4(0.3)$ & $6.5(0.3)$ & $6.3(0.3)$ & 0.11 \\
\hline & Range $6.0-7.1$ & & & \\
\hline Estimated GFR, $\mathrm{mL} / \mathrm{min} / 1.73 \mathrm{~m}^{2 \S}$ & $52.8( \pm 15.7)$ & $55.8(12.4)$ & $43.9(19.1)$ & $0.05^{*}$ \\
\hline & Range $21.7-79.5$ & & & \\
\hline BMI, $\mathrm{kg} / \mathrm{m}^{2}$ & $25.5(4.5)$ & $24.9(4.4)$ & $26.8(5.1)$ & 0.31 \\
\hline & Range $18.5-36.9$ & & & \\
\hline BMI, $n(\%)$ & & & & * \\
\hline$<25$ & $19(55.9)$ & $12(60.0)$ & $6(60.0)$ & \\
\hline $25-29$ & $10(29.4)$ & $6(30.0)$ & $1(10.0)$ & \\
\hline$\geq 30$ & $5(14.7)$ & $2(10.0)$ & $3(30.0)$ & \\
\hline \multicolumn{5}{|l|}{ Health status (SF-36) ${ }^{\mathrm{a}}$, mean (SD) } \\
\hline Physical functioning & $76.8(21.1)$ & $84.8(14.0)$ & $69.0(23.7)$ & $0.03 *$ \\
\hline Role-physical & $67.6(41.5)$ & $86.3(26.3)$ & $27.5(38.1)$ & $<0.01 * *$ \\
\hline Bodily pain & $70.6(25.2)$ & $76.7(22.1)$ & $64.1(26.5)$ & 0.18 \\
\hline General health & $54.1(19.1)$ & $60.8(19.3)$ & $42.9(14.7)$ & $0.02 *$ \\
\hline Vitality & $60.0(18.5)$ & $60.5(18.3)$ & $58.5(19.9)$ & 0.79 \\
\hline Social functioning & $80.1(21.1)$ & $86.3(17.2)$ & $68.8(23.0)$ & $0.03^{*}$ \\
\hline Role-emotional & $73.5(40.0)$ & $81.7(33.3)$ & $56.7(47.3)$ & 0.16 \\
\hline Mental health & $74.4(15.1)$ & $74.6(14.7)$ & $72.0(18.8)$ & 0.68 \\
\hline Fatigue $(\mathrm{CIS})^{\mathrm{b}}$, mean $(\mathrm{SD})$ & $29.2(12.9)$ & $26.0(12.7)$ & $33.9(10.9)$ & 0.10 \\
\hline
\end{tabular}

${ }^{a}$ Higher scores indicate higher levels of health status

${ }^{\mathrm{b}}$ Higher scores indicate higher levels of fatigue

$\S$ Statistical significance not tested due to empty cells or low expected frequencies

$* P \leq 0.05 ; * * \leq 0.01$ 
the general population $(n=1,742$; mean age 47.6 (SD 18.0); $56 \%$ male; [18]).

Fatigue was assessed by the subscale 'fatigue severity' of the Checklist Individual Strength (CIS) questionnaire [19] which consists of eight statements. Respondents indicate on a seven-point scale to what extent the particular statement applies to him or her. A higher score indicates a higher degree of subjective fatigue (range 8-56). A score of $\geq 35$ indicates severe fatigue [20]. Although the CIS originally was developed for the assessment of chronic fatigue syndrome this questionnaire was also validated in a working population [21]. In the present study Cronbach's alpha was 0.88 . The level of fatigue of transplant recipients was compared with data on fatigue in a working population ( $n=37$; mean age 35.0 [SD 6.4]; 49\% male; [21]).

\section{Work Outcomes}

Data on work status and disability benefits were measured three times (i.e., T1, T2, T3) by interview at patient's homes. Methodology of data collection is described in detail elsewhere [11, 22].

Work status was measured as the number of hours worked weekly according to contract, including selfemployed. Employment was classified as working for pay, i.e., full-time ( $\geq 30 \mathrm{~h} /$ week) or part-time (12-29 h/week). According to the definition of Statistics Netherlands, persons who worked less than $12 \mathrm{~h}$ per week were labelled as unemployed.

Disability benefit was defined as receiving either a full or partially social security benefit administered under the Work Incapacity Act (WAO) or the act on Work and Income according to Work Capacity (WIA). Those who received a disability pension were asked to consent to extract their data on functional limitations from the social security system database as filled out by social insurance physicians after clinical examination.

Work Ability Transplant recipients in the third wave (T3) study group who had a paid job ( $\geq 12 \mathrm{~h} /$ week) were asked to fill out the Work Ability Index questionnaire (WAI) [23], a summary measure of seven items (range 7-49). The WAI score is classified into poor (7-27), moderate (28-36), good (37-43) and excellent (44-49) work ability. WAI scores of transplant recipients were compared with normative data from the general working population ( $n=3,000$; five companies; data unpublished) and with a population aged $\geq 45$ years with a chronic disease ( $n=1,100$; mean age 53.3 (SD 4.8); 44\% male; [24]). Furthermore, the work ability trajectory of all recipients was examined retrospectively. For this purpose we used the first item of the WAI questionnaire, which asks patients to estimate their work ability compared with the lifetime best (range 0 [unable to work] to 10 [lifetime best]).
To minimize recall bias, patients were requested to estimate their work ability at three distinctive time points in the history of renal disease (i.e., diagnosis of ESRD; start of dialysis; admission for transplantation). Three additional aspects of work ability (i.e., physical capability, speed of work, ability to concentrate) were assessed accordingly.

Pattern of Work Outcomes For the description of the work outcomes during the ESRD trajectory we used the prospective posttransplantation data (T1, T2, T3), as well as the retrospective data on pretransplantation work outcomes which were assessed at baseline. For this purpose transplant recipients reported work status and disability benefits on the three distinctive time points in the history of renal disease as mentioned above.

Statistical Analysis

Non-response analysis, attrition analysis and analysis of differences between working and non-working study participants were performed with the independent sample $t$ test, the Mann-Whitney test and Chi-squared test. The Fisher's Exact test was used if expected frequencies were below five. Comparison with normative data was tested with the independent sample $t$ test. $P$ value $\leq 0.05$ (twosided) was considered statistically significant. Data analysis was performed using SPSS, version 16.0 (SPSS, Inc., Chicago).

\section{Results}

\section{Study Population}

The socio-demographic and clinical characteristics of the third wave study participants $(n=34)$ are outlined in Table 1 . Four recipients were aged $\geq 65$ years. Six patients (18.2\%) had diabetes mellitus (DM). Five patients developed DM posttransplantation and one patient had DM before onset of ESRD, but their ESRD was caused by glomerulonephritis. Three recipients developed posttransplantation lymphoproliferative disorder (PTLD). The mean time since transplantation was 6.4 years (range 6.0-7.1).

\section{Health Outcomes Long-Term After Transplantation}

Data on the SF-36 (Table 1) show that scores on the subscale 'general health' were lowest whereas scores on 'social functioning' were highest, indicating that transplant recipients were least restricted in social functioning. Comparison with normative data from the general population [18] indicated that transplant recipients had significantly lower level of general health perceptions (mean difference $-16.5 ; 95 \% \mathrm{CI}-23.2$ to $-9.9 ; P<0.001)$ and 
vitality (mean difference -8.6 ; $95 \%$ CI -15.1 to -2.1 ; $P<0.05)$. Differences on the other SF-36 subscales were not statistically significant although the physical functioning difference was of borderline significance $(P=0.09)$.

Application of a standard cutoff point $(\geq 35)$ classified 10 transplant recipients $(29.4 \%)$ as being 'severely fatigued'. Comparison of these results with fatigue in a working white collar population showed that transplant recipients had higher levels of fatigue (mean difference 8.8; 95\% CI 4.4-13.3; $P<0.001)$.

\section{Work Outcomes Long-Term After Transplantation}

Of the thirty recipients of working age ( $<65$ years), $67 \%$ $(n=20)$ were employed. Forty-five percent worked parttime $(<30 \mathrm{~h} /$ week $)$ and 2 recipients were self-employed. Median time to return to work after transplantation was 6 months (range 1-60). Of those employed, six recipients (30\%) were receiving disability benefits in addition to wages. Six recipients had a blue collar job, five had an administrative job, six did policy work, and three recipients had an executive job. At the time of data collection, one transplant recipient was on sick leave due to gout. For 12 recipients, it was a financial necessity to have a paid job as they were breadwinners. Other reasons for having a paid job listed were: social contact $(n=11)$, enjoy work $(n=10)$, nice colleagues $(n=6)$, importance of work $(n=6)$, and the opinion that one ought to work $(n=2)$. Of the 10 non-working recipients, five received a disability benefit, two recipients only had a minor job (3 and $10 \mathrm{~h}$, respectively), one was early retired, one recipient was looking for a job, and one recipient was a homemaker.

Comparison of non-working and working recipients (Table 1) shows that non-working recipients had significantly lower renal allograft function, lower physical, rolephysical and social functioning, and worse general health. The difference in fatigue was of borderline statistical significance $(P$ 0.10).

Thirty-seven percent $(n=11)$ of the study group were receiving some disability benefits ( $n=5$ full; $n=6$ partial) at the last follow-up. The recipients who were receiving a partial disability benefit also had a paid job (83\% part-time). Five recipients $(46 \%)$ reported that their disability was caused by ESRD and four recipients (36\%) reported that disability was related to a combination of ESRD and other chronic diseases such as systemic lupus erythematosus $(n=2)$, visual impairment $(n=1)$ and chronic fatigue $(n=1)$. Only two recipients $(18 \%)$ were disabled due to other diseases such as visual impairment $(n=1)$ and chronic low back pain $(n=1)$. Seven disabled recipients (64\%) reported a disagreement with the social insurance physician on their capability of weekly working hours: three recipients who were fully disabled had the opinion that they were able to work a maximum of $10 \mathrm{~h}$ per week, whereas four recipients stated that they were not capable to work the amount of hours as prescribed by the social insurance physician.

Six $(55 \%)$ of the disabled transplant recipients gave informed consent to extract data on functional limitations from the social security administration. Functional limitations as assessed by the social insurance physician were related to: special requirements for the physical work environment $(n=5)$, sustained and frequent bending $(n=4)$ and reaching $(n=3)$, pushing or pulling dynamic $(n=3)$, sustained and frequent lifting or carrying $(n=4)$, sustained and frequent handling of light $(n=2)$ and heavy $(n=5)$ objects, sustained walking $(n=4)$ and standing $(n=4)$, kneeling or squatting $(n=1)$, working above shoulder level $(n=3)$, stair climbing $(n=2)$, and alternating posture $(n=1)$. With respect to working hours, there were limitations in working in evening $(n=2)$ and night shifts $(n=2)$, in number of daily working hours $(n=4$; $\max 6 \mathrm{~h})$, and number of weekly working hours $(n=4$; $\max 30 \mathrm{~h})$.

The transplant recipients who had a paid job $(n=20)$ filled out the WAI questionnaire (mean score 36.3 (SD $5.3)$; range 27-46). The majority of the recipients $(n=12$; $60.0 \%$ ) had a moderate work ability and one recipient $(5 \%)$ had a poor work ability. The percentage of workers with good or excellent work ability was $20 \%$ and $15 \%$, respectively. Compared to a reference group of Dutch employees $(M=40.6)$, transplant recipients had a lower mean level of work ability (mean difference $-4.4 ; 95 \% \mathrm{CI}$ -6.8 to $-1.9 ; P<0.01)$. Compared to data from Dutch employees with a chronic disease $(M=35.3)$, they had a similar level of work ability (mean difference $0.95 ; 95 \% \mathrm{CI}$ -1.5 to $3.4 ; P=0.43$ ).

\section{Pattern of Work Outcomes During the ESRD Trajectory}

Figure 2 presents the pattern of work status and disability benefits of the third wave study participants throughout the ESRD trajectory (i.e., from the diagnosis of ESRD to longterm follow-up after transplantation). At the time that ESRD was diagnosed, $74 \%$ had a paid job. This proportion remained stable during the pre-dialysis phase $(72 \%$ employed at the start of dialysis). However, $26 \%$ of those employed were on full sick leave by then. Once dialysis had started, more patients quit working as evidenced by the decreased employment rate $(50 \%$ employed at transplantation). Moreover, $19 \%$ of those employed were on full sick leave at transplantation. In the first year after transplantation the proportion of patients with a paid job remained stable (53\% at 1 year follow-up) but then increased long-term (67\% at 6 years follow-up). 


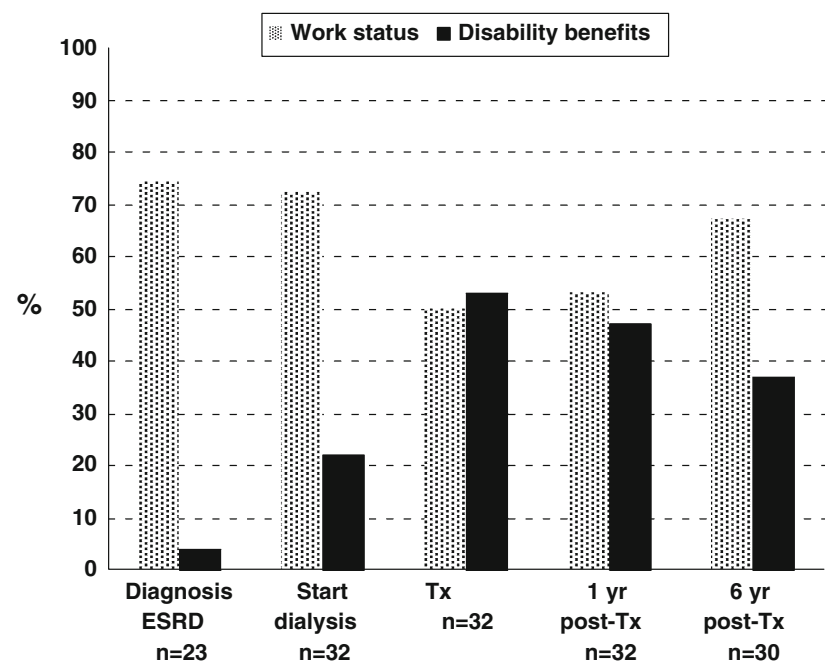

Fig. 2 Pattern of work status and disability benefits of the third wave study group during the ESRD disease trajectory (18-64 years). Tx transplantation. The sample size $(n)$ at each time point is based on the number of patients aged 18-64 years, full-time students excluded (at diagnosis, $n=6<18$ years, $n=1 \geq 65$ years, $n=4$ full-time students; at start dialysis, $n=1<18$ years, $n=1 \geq 65$ years; at Tx and 1 year post-Tx, $n=1 \geq 65$ years, $n=1$ full-time student; at 6 years post-Tx, $n=4 \geq 65$ years)

The pattern of disability benefits paralleled the pattern of work status, only in the opposite direction. The proportion of patients receiving a disability benefit increased preceding transplantation (4\% at diagnosis; $22 \%$ at start of dialysis; $53 \%$ at transplantation). One year post-transplantation $47 \%$ were receiving a disability benefit whereas in the long-term $37 \%$ remained disabled. With respect to the distinction between full and partial disability benefits the results indicated a decrease in full disability posttransplantation. Of those receiving a disability benefit, 59\% were fully disabled at transplantation, 53\% were fully disabled at 1 year follow-up, and $45 \%$ were fully disabled at 6 years follow-up, respectively. As a result, the proportion of partial disability benefits increased $(41 \%$ at transplantation; 47\% 1 year follow-up; 55\% 6 years follow-up). The assignment of a disability benefit was preceded by sick leave as reported in the previous paragraph (maximum duration of sick leave during employment in the Netherlands is 2 years).

The pattern of overall work ability of the third wave study group during the ESRD trajectory (Fig. 3) showed a decrease of work ability during the pre-dialysis phase which persisted throughout dialysis, but improved after transplantation. However, work ability long-term after transplantation was below the level of work ability preceding diagnosis of ESRD. There was a similar pattern for physical capability, speed of work and ability to concentrate. Ability to concentrate was the least affected aspect of work ability.

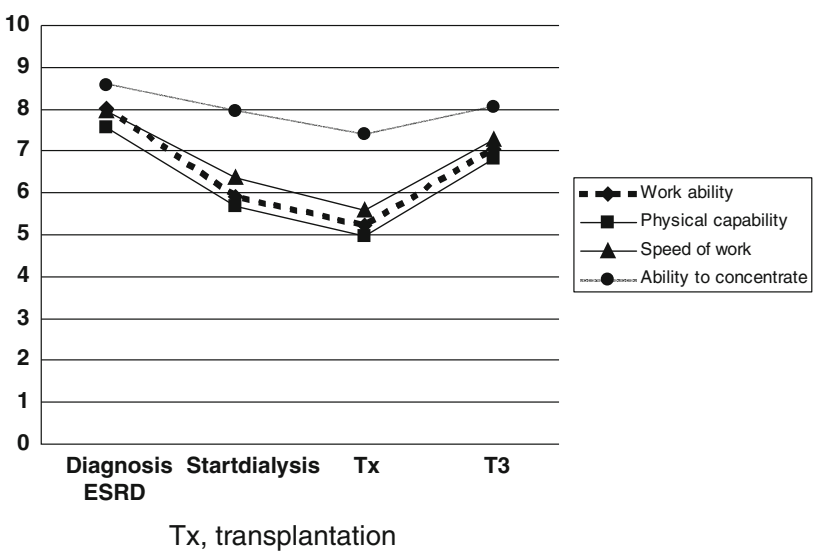

Fig. 3 Work ability of the third wave study group during the ESRD trajectory $(n=34)$

\section{Discussion}

This follow-up study described the health- and work outcomes in 34 renal transplant recipients long-term ( $>6$ years) after transplantation. The results showed that recipients reported worse general health and vitality compared to the general population which can be attributed to impaired physical functioning. A substantial number of the recipients were classified as severely fatigued. Non-working recipients had lower renal function, worse general health and more limitations in physical and social functioning compared to working recipients. Although work status improved after successful kidney transplantation, more than one third of the recipients with successful transplants still depended on disability benefits in the long-term. Of those employed, the majority had moderate work ability. Examination of work outcomes preceding transplantation indicates that renal failure causes sickness absence and leads to disability even before dialysis has started. During dialysis the proportion of recipients with disability benefits further increased. The results of our study demonstrated that a 'new' kidney does not necessarily leads to 'normal' work status and good work ability, but it has significant advantages compared to dialysis in this respect.

Our results on self-reported health status showed compromised general health in transplant recipients compared with the general population. Renal transplantation is accompanied by adverse effects and various complications [25]. Besides the increased risk for cardiovascular mortality [26], the lifelong use of immunosuppressive medication introduces new health risks such as hypertension [27], bone disorders [28], post-transplantation diabetes [29], and an increased risk for cancer [30] and infection. In addition, health status is affected by the side-effects of immunosuppressive medication [31]. Transplant recipients have to face these downsides in their day-to-day lives. 
The employment rate in the present study was $67 \%$ which is higher than most of the employment rates found in previous studies performed in other countries (range $18-82 \%[6-10,12,13,32,33])$. It is also higher than the employment rate we found in our cross-sectional study (48\%; minor jobs $<12 \mathrm{~h} /$ week excluded [11]). With respect to pretransplantation employment rates, the present study found higher rates compared to a Dutch study in ESRD patients that showed an employment rate of $51 \%$ in predialysis patients [34] and 24\% in dialysis patients [35], where we found 72 and $50 \%$, respectively. These higher rates may be explained by a better health status of our study participants during (pre-)dialysis which is one of the eligibility criteria for renal transplantation, as well as selection bias due to drop-out of older and sicker participants.

Differences in employment rates between studies may be related to differences in social legislation between countries. The Dutch legislation is focused on participation in the labour force and aims to prevent compensation of work loss. In the USA, the willingness of transplant recipients to return to work may be affected by the potential loss of disabilityrelated coverage for expensive immunosuppressive medication [36] which is clearly a barrier to employment [10]. In the Dutch social legislation system there is no connection between health insurance and disability benefits, and return to work is further encouraged by the possibility of supplementary partial disability benefits. This was the case in $30 \%$ $(n=6)$ of the employed recipients in our study.

A substantial number of our study group remained (partial) disabled (37\%) which is in line with previous studies. Overbeck et al. [7] found in a sample of German renal transplant recipients that $42 \%$ were permanently out of work due to disability. In a Belgian sample of four different organ transplants (i.e., kidney, heart, liver, lung), De Baere et al. [12] reported that $45 \%$ of the organ recipients were medically unable to work or received a disability benefit.

Disability in our study group appears to be primarily caused by physical impairment, as transplant recipients reported impaired general health and fatigue, and a decreased level of physical function work ability. Fatigue is known to be related to sickness absence [37] and work disability [38]. Likewise, poor work ability is a determinant of receiving disability benefits [39]. There is little available information about specific functional impairments in transplant recipients. Manninen et al. [40] reported that transplant recipients experienced functional limitations in reaching, reading and carrying weights. The majority of transplant recipients experience musculoskeletal disorders [41] which affect physical functioning [42]. For some patients the prospect of doing certain types of work therefore may be poor [40]. Our study participants also experienced functional limitations according to objective criteria (i.e., assessed by an social insurance physician) which resulted in a disability benefit. It can be assumed that those who are not disabled and are capable of having a job experience functional limitations as well, as we found impaired work ability and high levels of fatigue even in employed persons. Our results indicate that impaired work ability is common, but also indicates a substantial variation among transplant recipients. The relatively low point prevalence of patients on renal replacement therapy in the Netherlands ( $n=14.690$ [43]) and the consequently small number of these patients in social insurance physician's practices, may imply a lack of expertise. Together with the wide inter-rater variability between physicians in assessing disability [44] it is not surprising that we found a discrepancy in opinions between social insurance physicians and patients with respect to the capability of weekly working hours. A previous Dutch study found significant differences between self-reported work limitations and limitations as reported by social insurance physicians [45]. Hopefully, the recently developed practice guideline for social insurance physicians [46], which was developed in close cooperation with clinicians, social insurance physicians, occupational physicians, labour experts and a health scientist, may assist social insurance physicians in correctly assigning disability benefits to ESRD patients.

With respect to the pattern of work outcomes our study showed a substantial loss of work during the pre-dialysis phase as well as during dialysis. Obviously, the decline in renal function is accompanied by a decline in physical and functional capacity [47] resulting in an impaired work ability [48] and sickness absence. Dialysis, which is an invasive and time consuming treatment, further deteriorates ability to participate in work [12, 49], which improves after transplantation. Several studies point out that pretransplant work status is an important determinant of work status posttransplantation [8, 12, 13, 32, 33]. Vocational rehabilitation, which should have a multidisciplinary approach [50], may help ESRD patients to maintain their work [51, 52].

The examination of work outcomes throughout the ESRD trajectory, the long-term follow-up after transplantation, and the data collection at relatively the same length of time after transplantation in each study participant are strengths of the present study. In addition, our study was able to obtain data on functional limitation ratings from the social security system database. However, there are some shortcomings. The relatively small third wave study group represents a selective sample from the cohort of patients that were transplanted in 2002 and 2003. Study participants had a higher educational level and less often received disability benefits at baseline compared to those who were lost to follow-up. This may have resulted in a higher work status and less disability benefits. Therefore, our study probably overestimates work status and underestimates 
disability benefit outcomes in renal transplant recipients. Moreover, it is not clear if our study group is representative for patients transplanted at other centres in the Netherlands. Therefore, this study should be regarded as a pilot study that triggers the development of larger studies. Lastly, the retrospective part of the baseline interview that requested patients to recall their work status as well as the retrospective assessment of work ability may have introduced recall bias. Despite these limitations our study contributes to the understanding of the pattern of work status in renal transplant recipients.

Our study demonstrated that patients during their ESRD 'career' are confronted with decreased work ability, sickness absence and work disability. However, there are also good prospects for maintaining work during this trajectory, and return to sustainable work after transplantation. These transitions may require adaptation not only by patients but also by their work and living environments. Because of the complexity of problems and limitations ESRD patients experience, vocational rehabilitation, preferably with a multidisciplinary approach, may be helpful [53]. Job retention during (pre-)dialysis should be one of the aims of these interventions, because it is easier to return to work after a period of sick leave caused by the transplantation, than to find a new job. Patients should remain actively employed as long as possible before transplantation [12]. However, for many patients, maintaining employment during (pre-)dialysis is only feasible with significant work modifications, such as the reduction of working hours and work tasks, and sufficient control over the working situation, in order to fit in treatment with working life. Interventions based on empowerment and self-management of ESRD patients may be worthwhile [51, 54, 55]. Nephrology professionals have a key role in the assessment of work-related problems. They should not only pay more attention to this issue but also cooperate and communicate with vocational rehabilitation specialists [46].

Acknowledgments The authors would like to thank Marike van Kalken, PreventNed BV, Enschede, for supporting the norm data of the Work Ability Index. In addition, the authors are grateful for the contribution of Henny Mulders from the Social Security Office, the Netherlands. This study was supported by a grant from the Dutch Kidney Foundation (SB94).

Open Access This article is distributed under the terms of the Creative Commons Attribution Noncommercial License which permits any noncommercial use, distribution, and reproduction in any medium, provided the original author(s) and source are credited.

\section{References}

1. Wolfe RA, Ashby VB, Milford EL, et al. Comparison of mortality in all patients on dialysis, patients on dialysis awaiting transplantation, and recipients of a first cadaveric transplant. N Engl J Med. 1999;341:1725-30.

2. Kaplan B, Meier-Kriesche HU. Renal transplantation: a half century of success and the long road ahead. J Am Soc Nephrol. 2004:15:3270-1.

3. Goodman WG, Danovitch GM. Options for patients with endstage renal disease. In: Danovitch GM, editor. Handbook of kidney transplantation. Philadelphia: Lippincott Williams and Wilkins; 2001. p. 1-16.

4. Luk WS. The HRQoL of renal transplant patients. J Clin Nurs. 2004;13:201-9.

5. Cohen D, Galbraith C. General health management and long-term care of the renal transplant recipient. Am J Kidney Dis. 2001;38: S10-24.

6. Van der Mei SF, Krol B, van Son WJ, de Jong PE, Groothoff JW, van den Heuvel WJA. Social participation and employment status after kidney transplantation: a systematic review. Qual Life Res. 2006;15:979-94.

7. Overbeck I, Bartels M, Decker O, Harms J, Hauss J, Fangmann J. Changes in quality of life after renal transplantation. Transplant Proc. 2005;37:1618-21.

8. Bohlke M, Marini SS, Gomes RH, et al. Predictors of employment after successful kidney transplantation-a population-based study. Clin Transplant. 2008;22:405-10.

9. Raiz L, Monroe J. Employment post-transplant: a biopsychosocial analysis. Soc Work Health Care. 2007;45:19-37.

10. Monroe J, Raiz L. Barriers to employment following renal transplantation: implications for the social work professional. Soc Work Health Care. 2005;40:61-81.

11. Van der Mei SF, van Sonderen EL, van Son WJ, de Jong PE, Groothoff JW, van den Heuvel WJ. Social participation after successful kidney transplantation. Disabil Rehabil. 2007;29: 473-83.

12. De Baere C, Delva D, Kloeck A, et al. Return to work and social participation: does type of organ transplantation matter? Transplantation. 2010;89:1009-15.

13. Matas AJ, Lawson W, McHugh L, et al. Employment patterns after successful kidney transplantation. Transplantation. 1996;61: 729-33.

14. Van der Mei SF, van Son WJ, van Sonderen EL, de Jong PE, Groothoff JW, van den Heuvel WJ. Factors determining social participation in the first year after kidney transplantation: a prospective study. Transplantation. 2007;84:729-37.

15. United Nations Educational Scientific and Cultural Organization (UNESCO). International standard classification of education (ISCED). Genève: UNESCO; 1997.

16. ERA-EDTA Registry. ERA-EDTA registry 2003 Annual Report. Academic Medical Center, Amsterdam, The Netherlands; 2005.

17. Levey AS, Greene T, Kusek JW, Beck GJ, MDRD study group. A simplified equation to predict glomerular filtration rate from serum creatinine. J Am Soc Nephrol. 2000;11:155A.

18. Aaronson NK, Muller M, Cohen PD, et al. Translation, validation, and norming of the Dutch language version of the SF-36 health survey in community and chronic disease populations. J Clin Epidemiol. 1998;51:1055-68.

19. Vercoulen JH, Swanink CM, Fennis JF, Galama JM, van der Meer JW, Bleijenberg G. Dimensional assessment of chronic fatigue syndrome. J Psychosom Res. 1994;38:383-92.

20. Van Hoogmoed D, Fransen J, Bleijenberg G, van Riel P. Physical and psychosocial correlates of severe fatigue in rheumatoid arthritis. Rheumatology (Oxford). 2010;49:1294-302.

21. Beurskens AJ, Bultmann U, Kant I, Vercoulen JH, Bleijenberg G, Swaen GM. Fatigue among working people: validity of a questionnaire measure. Occup Environ Med. 2000;57:353-7.

22. Van der Mei SF, Groothoff JW, van Sonderen EL, van den Heuvel WJ, de Jong PE, van Son WJ. Clinical factors influencing 
participation in society after successful kidney transplantation. Transplantation. 2006;82:80-5.

23. Tuomi K, Ilmarinen J, Jahkola A, Katajarinne L, Tulkki A. Work ability index. Helsinki: Finnish Institute of Occupational Health; 1998.

24. Koolhaas W, van der Klink JJL, Groothoff JW, Brouwer S. Towards a sustainable healthy working life: associations between chronological age, functional age and work outcomes. Eur J Public Health. 2011. doi:10.1093/eurpub/ckr035.

25. Bemelman FJ, ten Berge RJ. Late complications following renal transplantation. Ned Tijdschr Geneeskd. 2008;152:1317-21.

26. Pham PT, Pham PC, Danovitch GM. Cardiovascular disease posttransplant. Semin Nephrol. 2007;27:430-44.

27. Zhang R, Leslie B, Boudreaux JP, Frey D, Reisin E. Hypertension after kidney transplantation: impact, pathogenesis and therapy. Am J Med Sci. 2003;325:202-8.

28. Sprague SM, Josephson MA. Bone disease after kidney transplantation. Semin Nephrol. 2004;24:82-90.

29. Balla A, Chobanian M. New-onset diabetes after transplantation: a review of recent literature. Curr Opin Organ Transplant. 2009; $14: 375-9$.

30. Wong G, Chapman JR. Cancers after renal transplantation. Transplant Rev (Orlando). 2008;22:141-9.

31. Rosenberger J, van Dijk JP, Nagyova I, et al. Predictors of perceived health status in patients after kidney transplantation. Transplantation. 2006;81:1306-10.

32. Markell MS, DiBenedetto A, Maursky V, et al. Unemployment in inner-city renal transplant recipients: predictive and sociodemographic factors. Am J Kidney Dis. 1997;29:881-7.

33. Raiz L. The transplant trap: the impact of health policy on employment status following renal transplantation. J Health Soc Policy. 1997;8:67-87.

34. Jansen DL, Grootendorst DC, Rijken M, et al. Pre-dialysis patients' perceived autonomy, self-esteem and labor participation: associations with illness perceptions and treatment perceptions. A cross-sectional study. BMC Nephrol. 2010;11:35.

35. Jansen DL, Rijken M, Heijmans M, Boeschoten EW. Perceived autonomy and self-esteem in Dutch dialysis patients: the importance of illness and treatment perceptions. Psychol Health. 2010; 25:733-49.

36. Slakey DP, Rosner M. Disability following kidney transplantation: the link to medication coverage. Clin Transplant. 2007;21: 224-8.

37. Janssen N, Kant IJ, Swaen GM, Janssen PP, Schroer CA. Fatigue as a predictor of sickness absence: results from the Maastricht cohort study on fatigue at work. Occup Environ Med. 2003; 60(Suppl 1):i71-6.

38. Van Amelsvoort LG, Kant IJ, Beurskens AJ, Schroer CA, Swaen GM. Fatigue as a predictor of work disability. Occup Environ Med. 2002;59:712-3.

39. Alavinia SM, de Boer AG, van Duivenbooden JC, Frings-Dresen $\mathrm{MH}$, Burdorf A. Determinants of work ability and its predictive value for disability. Occup Med (Lond). 2009;59:32-7.
40. Manninen DL, Evans RW, Dugan MK. Work disability, functional limitations, and the health status of kidney transplantation recipients posttransplant. Clin Transplant. 1991;193-203.

41. Atallah AM, Farag SM, Senna MK, Ghoneim MA. Musculoskeletal affections among kidney recipients: prevalence and risk predictors. Rheumatol Int. 2008;28:1085-90.

42. Blake C, Codd MB, Cassidy A, O'Meara YM. Physical function, employment and quality of life in end-stage renal disease. J Nephrol. 2000;13:142-9.

43. Dutch End-Stage Renal Disease Registry (RENINE). Statistical data 2010. Available from: http://www.renine.nl/static?id=prev_ years \&var $=$ dg \& style $=$ line \&render $=$ png.

44. Spanjer J, Krol B, Brouwer S, Groothoff JW. Sources of variation in work disability assessment. Work. 2010;37:405-11.

45. Brouwer S, Dijkstra PU, Stewart RE, Goeken LN, Groothoff JW, Geertzen JH. Comparing self-report, clinical examination and functional testing in the assessment of work-related limitations in patients with chronic low back pain. Disabil Rehabil. 2005;27: 999-1005.

46. Institution of insurance medicine. Insurance guidelines: borderline personality disorder and chronic renal failure. Utrecht: Dutch Federation for Insurance Medicine (NVVG); 2009.

47. Heiwe S, Clyne N, Dahlgren MA. Living with chronic renal failure: patients' experiences of their physical and functional capacity. Physiother Res Int. 2003;8:167-77.

48. Neri L, Gallieni M, Cozzolino M, et al. Work ability and health status in dialysis patients. Int J Artif Organs. 2005;28:554-6.

49. Van Manen JG, Korevaar JC, Dekker FW, Reuselaars MC, Boeschoten EW, Krediet RT. Changes in employment status in end-stage renal disease patients during their first year of dialysis. Perit Dial Int. 2001;21:595-601.

50. Carter JM, Winsett RP, Rager D, Hathaway DK. A center-based approach to a transplant employment program. Prog Transplant. 2000;10:204-8.

51. Rasgon S, Schwankovsky L, James-Rogers A, Widrow L, Glick J, Butts E. An intervention for employment maintenance among blue-collar workers with end-stage renal disease. Am J Kidney Dis. 1993;22:403-12.

52. Kutner N, Bowles T, Zhang R, Huang Y, Pastan S. Dialysis facility characteristics and variation in employment rates: a national study. Clin J Am Soc Nephrol. 2008;3:111-6.

53. King K. Multidisciplinary contributions to rehabilitation: a National Kidney Foundation survey of the dialysis health care team. Adv Ren Replace Ther. 2003;10:78-83.

54. Rasgon SA, Chemleski BL, Ho S, et al. Benefits of a multidisciplinary predialysis program in maintaining employment among patients on home dialysis. Adv Perit Dial. 1996;12:132-5.

55. Varekamp I, Verbeek JH, van Dijk FJ. How can we help employees with chronic diseases to stay at work? A review of interventions aimed at job retention and based on an empowerment perspective. Int Arch Occup Environ Health. 2006;80: 87-97. 